\title{
Are the Benefits of Value-Based Insurance Design Conclusive?
}

\author{
Joel F. Farley, PhD
}

\section{Farley's Viewpoint} significance of improvements to medication adherence resulting from valuebased insurance design (VBID) policies persist in the literature. Given the lack of conclusive evidence about effectiveness, in addition to concerns about the cost of implementing VBID programs, it is perhaps not surprising that VBID is not more widely used by managed care plans. Although VBID holds promise for improving chronic medication use, additional evidence is needed if VBID is to become universally adopted.

J Manag Care Spec Pharm. 2019;25(7):736-38

Copyright $\odot 2019$, Academy of Managed Care Pharmacy. All rights reserved.

T he theory of value-based insurance design (VBID) posits that high-value, evidence-based services should have lower cost-sharing requirements, while low-value services should face higher cost sharing. ${ }^{1,2}$ Under this model, if the use of a medication improves patient health and is cost-effective, then reducing the cost of the medication to patients should improve the patient's ability to obtain treatment and result in better medication adherence, access, and patient health. Although simple in theory, I would argue that results from VBID evaluations have generally fallen short of expectations. This has led to questions regarding the benefits of VBID and slowed its adoption.

\section{Where Is the Evidence?}

A 2014 systematic review of the VBID literature published up to 2012 identified 10 studies that examined outcomes from VBID implementation. ${ }^{3}$ Of the studies conducted, there was 1 high-quality randomized controlled trial (RCT) and 9 observational studies with sufficient design to draw potential causality between the program and outcomes. Among the studies included in the review, the studies that examined medication adherence showed a 2-5 percentage-point improvement in adherence to chronic medications. This finding calls into question the clinical significance of VBID as a tool to improve medication use. To illustrate, a patient who is $80 \%$ adherent to a chronic medication used once daily would use that medication 292 days in a year. A 5\% improvement in adherence would correspond to an additional 18 days of medication use per year on average, and a $2 \%$ adherence improvement would correspond to an additional 7 days of treatment.

Questions about clinical significance are further enforced when looking at clinical outcomes. The MI FREEE trial, which is the only RCT included in the systematic review, showed no effect on the primary outcome of interest, which was defined as first readmission for a major vascular event or coronary revascularization following a myocardial infarction. ${ }^{4}$ As the only VBID RCT to date, the lack of clinical significance found in this study calls into question the benefits of VBID.

Following the publication of the 2014 systematic review, the VBID literature has continued to grow. Additional literature reviews of VBID benefits have found similar results, with an average 3\% improvement in adherence reported across studies., ${ }^{5,6}$ In a more recent literature review, the evidence of benefit from VBID was graded as "moderately" conclusive on the basis of quality, with some questions of benefit remaining. ${ }^{7}$ In addition to inconclusive evidence of benefit, the cost that health plans face from lost revenue when waiving copayments presents another consideration that may influence the decision about whether to adopt VBID programs.

In addition to lack of consensus regarding clinical benefit, the evidence of economic benefit from adopting VBID policies is even more scant. Of the 4 studies that examined health care spending results from VBID in the 2014 systematic review, 3 found no difference in total health care spending between patients enrolled in VBID and those not enrolled. ${ }^{3}$ One study, which examined health care costs resulting from waiving copayments for 8 chronic therapeutic categories of medication in patients with hypertension and coronary artery disease, found a $\$ 5.7$ million reduction in health care spending resulting from the program. However, this reduction was offset by a $\$ 6.4$ million increase in medication expenditures borne by the insurer in part through absorbing the copayment burden previously covered by patients. ${ }^{8}$ Given the marginal benefit to medication adherence and the additional cost of administering this program, the insurer that had adopted this program discontinued its participation. Even the most recent review of the VBID literature, which graded the quality of evidence related to VBID, suggested that, at best, VBID does not increase total health care spending.?

\section{Implementation Matters}

What is clear from a review of the literature regarding the application of VBID to prescription drug benefit is that there is not currently a one-size-fits-all model for implementation. One of the more common models used by health plans to implement VBID is to make high value therapeutic medication classes free or at reduced copayment rates to patients. This method of implementation, although easy to adopt, shows inefficiency in its method of targeting. Despite the amount of literature demonstrating problems with medication adherence, many 
patients adhere to their medications regardless of whether they pay a copayment or not. Making medications free to patients for whom cost is a barrier under VBID models means that the benefits also extend to patients who would otherwise be able to afford their medication regardless of reduced copayment. Interestingly, in 1 study, which stratified VBID participants on baseline rates of adherence, previously nonadherent $(<50 \%)$ and partially adherent (50\%-79\%) patients had much bigger improvements in adherence following VBID than patients who were previously adherent $(\geq 80 \%){ }^{9}$

Another option to implement VBID relies not on use of specific high-value medication classes, but instead on the occurrence of a high-risk event. The MI FREE trial enrolled patients into a VBID program after a myocardial infarction. ${ }^{4}$ The potential advantage of this method of VBID is that it targets patients at a period of vulnerability, when there is good evidence to support the use of essential medications and a high risk for adverse events from inappropriate medication management. It also allows for more specific targeting of the VBID policy and reduces potential inefficiencies associated with waiving copayments for all patients regardless of risk. To our knowledge, this is the only VBID program that has targeted copayment reductions in high-risk patients during a period of vulnerability. As previously mentioned, the results were modest in clinical significance.

More recently, the concept of VBID has been combined with another commonly accepted principle in managed care: the placement of medications into formulary tiers based on cost-effectiveness. This method of implementation, which is mentioned by Yeung in his response to this article, has been termed value-based drug formularies (VBDF) in research that he and his colleagues have conducted. ${ }^{10,11}$ This implementation method for VBID tackles a challenge that is not addressed by simply waiving copayments to improve the use of high-value medications. It addresses inefficiencies associated with overutilization of low-value services by applying higher copayment rates to medications with lower clinical value. Addressing the overuse of low-value drugs confronts more than just the need to improve adherence but also addresses inefficiencies in plan spending. This method also addresses a potential inefficiency associated with blanket copayment waivers for entire therapeutic classes in that it allows for differential copayments within a therapeutic category when different drugs may have differential cost-effectiveness.

The most comprehensive evaluation of VBDF, conducted by Yeung et al. (2017), to date suggests a potential challenge with implementing this type of VBID design. ${ }^{11}$ In this study, the researchers examined payments to health plans and patients associated with the implementation of this program and found a $9 \%$ increase in medication expenditures by patients and a
$16 \%$ reduction to health plans. ${ }^{11}$ These findings suggest that although there was an overall benefit of the program to the health system, for patients using low-value medications, there is an increase in out-of-pocket spending. Patients lack the same degree of clinical information that prescribers have to assess the value and benefit of different types of medication. Initiating a VBDF program requires a response from patients regarding their willingness to purchase medication and seek alternative options from their providers to switch to high-valued costeffective treatments, which may not always happen.

\section{If Not VBID, Then What?}

In addition to aligning the selection of medications to highvalue treatments, one of the goals of VBID is to promote better medication adherence by reducing the cost burden to patients. However, cost is only one of many factors that influence whether a patient adheres to treatment. In a report from the World Health Organization (WHO), 5 different types of factors were identified as contributors to adherence to medical treatments. ${ }^{12}$ These contributors included health system factors (e.g., patient cost-sharing requirements addressed by VBID); social/economic factors (e.g., patient knowledge and beliefs); and condition-related factors (e.g., severity of symptoms). Even among the health system factors reported to influence adherence in the WHO report, cost sharing is just one of many factors that can influence adherence. Providing incentives to health plans to improve medication adherence under the Centers for Medicare \& Medicaid Services star ratings program is another example of a health system factor that has shown promise. Under this program, adherence to oral diabetes medications, antihypertensive medications, and statins have demonstrated significant improvements in adherence rates for targeted chronic medication classes plans over time. ${ }^{13}$

Given the complexity of this issue, it is perhaps not surprising that VBID does not present a single panacea for the issue of poor medication adherence to chronic treatments. As highlighted in the literature reviews of VBID evidence, to address the complexity of improving medication use, many plans implementing VBID policies have also adopted disease management programs, ${ }^{3,5,7}$ which present challenges to evaluation of the independent effect of VBID on clinical outcomes. However, at the macro level, it shows a challenge associated with the adoption of VBID, which alone may not be enough to improve medication use, given other potential challenges that patients face in managing their health. For patients who do not buy into the benefits of using a medication or who challenge the severity of their conditions, there is little incentive to use medication even if it is free. 


\section{Authors}

JOEL F. FARLEY, PhD, Department of Pharmaceutical Care \& Health Systems, University of Minnesota College of Pharmacy, Minneapolis.

AUTHOR CORRESPONDENCE: Joel F. Farley, PhD, Professor, Department of Pharmaceutical Care $\&$ Health Systems, University of Minnesota College of Pharmacy, 7-159D Weaver-Densford Hall, 308 Harvard St. S.E., Minneapolis, MN 55455. Tel.: 612.624.9624; E-mail:farl0032@umn.edu.

\section{DISCLOSURES}

No funding contributed to the writing of this article. The author currently receives funding from Blue-Cross Blue-Shield of Minnesota for unrelated research.

\section{REFERENCES}

1. Fendrick AM, Smith DG, Chernew ME, Shah SN. A benefit-based copay for prescription drugs: patient contribution based on total benefits, not drug acquisition cost. Am J Manag Care. 2001;7(9):861-67.

2. Gibson TB, Maclean RJ, Chernew ME, Fendrick AM, Baigel C. Valuebased insurance design: benefits beyond cost and utilization. Am J Manag Care. 2015;21(1):32-35.

3. Tang KL, Barnieh L, Mann B, et al. A systematic review of value-based insurance design in chronic diseases. Am J Manag Care. 2014;20(6):e229-41. 4. Choudhry NK, Avorn J, Glynn RJ, et al. Full coverage for preventive medications after myocardial infarction. N Engl J Med. 2011;365(22):2088-97.
5. Look KA. Value-based insurance design and medication adherence: opportunities and challenges. Am J Manag Care. 2015;21(1):e78-90.

6. Lee JL, Maciejewski M, Raju S, Shrank WH, Choudhry NK. Value-based insurance design: quality improvement but no cost savings. Health Aff (Millwood). 2013;32(7):1251-57.

7. Agarwal R, Gupta A, Fendrick AM. Value-based insurance design improves medication adherence without an increase in total health care spending. Health Aff (Millwood). 2018;37(7):1057-64.

8. Maciejewski ML, Wansink D, Lindquist JH, Parker JC, Farley JF. Valuebased insurance design program in North Carolina increased medication adherence but was not cost neutral. Health Aff (Millwood). 2014;33(2):300-08

9. Farley JF, Wansink D, Lindquist JH, Parker JC, Maciejewski ML.

Medication adherence changes following value-based insurance design. Am J Manag Care. 2012;18(5):265-74.

10. Sullivan SD, Yeung K, Vogeler C, et al. Design, implementation, and first-year outcomes of a value-based drug formulary. J Manag Care Spec Pharm. 2015;21(4):269-75. Available at: https://www.jmcp.org/doi/10.18553/ jmcp.2015.21.4.269.

11. Yeung K, Basu A, Hansen RN, Watkins JB, Sullivan SD. Impact of a value-based formulary on medication utilization, health services utilization, and expenditures. Med Care. 2017;55(2):191-98

12. Sabaté E, ed. Adherence to long-term therapies: evidence for action. 2003. World Health Organization. Available at: https://www.who.int/chp/ knowledge/publications/adherence_report/en/. Accessed May 27, 2019.

13. Centers for Medicare \& Medicaid Services. Trends in Part C \& D star ratings measure cut points. Last updated December 19, 2018. Available at: https://www.cms.gov/Medicare/Prescription-Drug-Coverage/ PrescriptionDrugCovGenIn/Downloads/2019_Cut_Point_Trend.pdf. Accessed May 27, 2019.

\title{
Value-Based Insurance Design: Current Evidence and Future Directions
}

\author{
Kai Yeung, PharmD, PhD
}

\section{Yeung's Viewpoint}

\section{SUMMARY}

Value-based insurance design (VBID) is an approach to designing insurance to align the use of health care services with some notion of value. While there is substantial federal interest in VBID and a growing body of evidence of its effects among populations covered by employer-sponsored plans, much of the focus has been on VBIDs that solely reduce cost sharing for certain treatments. The minority of VBIDs that have identified and increased cost sharing for low-value treatments have produced some promising results. Looking to the future, health plans should continue to develop and benefit from innovations in formulary design and health information technology that distinguishes and incentivizes high-value drugs in a patient-specific manner.

J Manag Care Spec Pharm. 2019;25(7):738-41

Copyright $\odot 2019$, Academy of Managed Care Pharmacy. All rights reserved.
T he United States spends nearly twice as much per capita on prescription drugs, compared with 10 of the highestincome countries. ${ }^{1}$ Value-based insurance design (VBID) has been proposed as a means to obtain better value for money. Broadly defined, VBID is an approach to designing insurance to align use with some notion of value. One form of VBID, lowering cost sharing for certain chronic conditions, has gained traction in federal policy during the past decade. For instance, the Patient Protection and Affordable Care Act required health plans to waive cost sharing for certain preventive services and drugs and promoted the establishment of guidelines to implement VBID in individual and group insurance markets. ${ }^{2}$ 